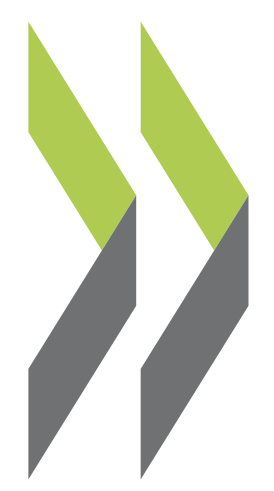

OECD Regional Development Working Papers 2019/06

Classifying small (TL3) regions based

on metropolitan population, low density and remoteness

\section{Milenko Fadic,}

\section{José Enrique Garcilazo,}

Ana Moreno Monroy,

Paolo Veneri 


\title{
Classifying small (TL3) regions based on metropolitan population, low density and remoteness
}

\author{
By: Milenko Fadic; José Enrique Garcilazo; Ana Moreno Monroy; and \\ Paolo Veneri
}

This paper provides a method to classify TL3 regions across OECD countries based on their level of access to metropolitan areas. TL3 regions are classified as 'metropolitan' if more than half of their population lives in one or more functional urban area (FUA) of at least 250 thousand inhabitants and as 'non-metropolitan' otherwise. The method sub-classifies metropolitan regions into 'large metro' or 'metro' regions based on the population size of the FUAs located within those regions. Non-metropolitan TL3 regions are sub-classified into: with access to a metro, with access to a small/medium city, or remote based on their level of access to a FUA with population above a predetermined threshold. The method relies on publicly available grid-level population data and localised information on driving conditions.

Key words: Indigenous peoples, place, well-being, regional and rural development, sustainable development goals, culture:

JEL codes: C80; R41; R52, R58 


\section{ABOUT THE OECD}

The OECD is a multi-disciplinary inter-governmental organisation of 36 member countries which engages in its work an increasing number of non-members from all regions of the world. The Organisation's core mission today is to help governments work together towards a stronger, cleaner, fairer global economy. Through its network of 250 specialised committees and working groups, the OECD provides a setting where governments compare policy experiences, seek answers to common problems, identify good practice, and coordinate domestic and international policies.

\section{ABOUT THE REGIONAL DEVELOPMENT WORIING PAPERS}

OECD Regional Development Working Papers cover a full range of topics including regional statistics and analysis, urban governance and economics, rural governance and economics, and multi-level governance. Depending on the programme of work, the papers can cover specific topics such as regional innovation and networks, the determinants of regional growth or fiscal consolidation at the sub-national level. OECD Regional Development Working Papers are published on http://www.oecd.org.cfe/regional-policy.

This paper is published under the responsibility of the Secretary-General of the OECD. The opinions expressed and the arguments employed herein do not necessarily reflect the official views of OECD member countries.

This paper was authorised for publication by Lamia Kamal-Chaoui, Director, Centre for Entrepreneurship, SMEs, Regions and Cities.

This document, as well as any statistical data and map included herein, are without prejudice to the status of or sovereignty over any territory, to the delimitation of international frontiers and boundaries and to the name of any territory, city or area.

C OECD 2019 You can copy, download or print OECD content for your own use, and you can include excerpts from OECD publications, databases and multimedia products in your own documents, presentations, blogs, websites and teaching materials, provided that suitable acknowledgment of OECD as source and copyright owner is given. All requests for commercial use and translation rights should be submitted to rights@ oecd.org. 


\section{Introduction ${ }^{1}$}

The OECD Regional Database collects and publishes statistical indicators at two different geographical levels, namely large regions (Territorial Level 2, TL2) and small regions (Territorial Level 3, TL3). Both levels encompass entire national territories. With some exceptions, TL2 regions represent the first administrative tier of subnational government (i.e. States in the United States, Provinces in Canada, or Régions in France). TL3 regions are smaller territorial units that make-up each TL2 region.

Since the creation of the Regional Database, the OECD has provided classifications of regions based on key characteristics of those regions, with the objective of providing a tool to analyse and better understand regional development issues. For example, the OECD urban-rural typology classifies TL3 regions into: predominantly urban, intermediate and predominantly rural (see Box 1 for details). The OECD extended urban-rural typology includes the remoteness dimension in predominantly rural regions, creating two subcategories: rural regions close to cities and rural remote (Brezzi, Dijkstra and Ruiz, $\left.2011_{[1]}\right)$.

This paper provides a new method to classify small regions (TL3) based on the level of access to metropolitan areas. The proposed classification distinguishes between 'metropolitan' and 'non-metropolitan' regions. Further, the method sub-classifies 'metropolitan' regions in 'large metro' and 'metro' regions, based on population size of the metropolitan areas located in those regions. Similarly, 'non-metropolitan' regions are subclassified in regions with access to a large city, to a small/medium city, or remote. The classification relies on a consistent concept of metropolitan area, which consists of functional urban areas (FUAs) of at least 250,000 inhabitants (OECD, 2012) (see Box 2 for details).

The purpose of the resulting classification is to help assess differences in socio-economic trends in regions - both within and across countries - by controlling for the presence/absence of metropolitan areas and the extent to which the latter is accessible by the population living in each region. The method emphasises the role of market access and rural-urban linkages and uses functional urban areas (FUAs) as the concept of reference for the classification. The method is meant to complement, rather than substitute, the existing urban-rural classification at the TL3 regional level (Brezzi, Dijkstra and Ruiz, 2011 ${ }_{[1]}$ ).

The concept of Functional Urban Area (FUA) was developed by the OECD in close cooperation with the European Commission (EC) to define cities and their surrounding areas of influence consistently across countries (OECD, 2012 $[2])$. The definition of Functional Urban Areas (FUAs) provides an internationally comparable measure of urban economic agglomerations. FUAs consist of groups of contiguous local jurisdictions (i.e. municipalities in most countries) that are aggregated based on functional criteria (see Box 2 for details). For the purpose of the proposed classification, each FUA is assigned to one

\footnotetext{
${ }^{1}$ Authors would like to acknowledge all delegates of the OECD Working Party on Territorial Indicators and of the Working Party on Rural Policy for their feedback on different versions of the paper. Comments and suggestions by Ray D. Bollman and by colleagues in the OECD Centre for Entrepreneurship, SMEs, Regions and Cities are also kindly acknowledged, in particular those by Rudiger Ahrend, Karen Maguire, and Joaquim Oliveira Martins.
} 
of two categories based on FUA size: "small/medium city" (short for small/medium FUAs), including all FUAs larger than 50 thousand and smaller than 250 thousand; or "metro" (short for metropolitan FUAs), including FUAs with at least 250 thousand inhabitants. ${ }^{2}$

Combining regional data at a TL3 scale with the FUA definition into a regional typology based on access to FUAs has recently become possible given the increasing availability of grid-based population data as well as comparable sources of geographical access based on road network data. A definition based on functionality rather than on density can also help bringing a clearer meaning to the aggregation of economic variables measured at the regional scale (such as GDP). ${ }^{3}$

A classification based on FUAs has been already carried out for TL3 regions in Europe by the European Commission and classifies regions as 'metropolitan' or 'non-metropolitan' (Eurostat, 2013 $3_{[3]}$ ). The method proposed in this paper is consistent with such a classification by the European Commission and it extends it in two ways. First, it distinguishes 'large metro' regions (MR-L) from 'metro' regions (MR-M) based on the minimum population size of the FUAs located in the region (1.5 million and 250000 inhabitants, respectively). Second, the proposed method further classifies all nonmetropolitan regions (NMR) into three categories: with access to a metro (NMR-M), with access to a small/medium city (NMR-S), or remote (NMR-R).

The results show that across OECD countries $71 \%$ of the population lives in metropolitan regions $-42 \%$ in large metro regions and $29 \%$ in other metro regions. The remaining $29 \%$ of people live in non-metropolitan regions. They are distributed in regions with access to a metro (12\%), with access to a small/medium city (9\%), and remote (8\%). Regarding the total number of regions, $37 \%$ of OECD TL3 regions are classified as metropolitan, of which $13 \%$ as large metro regions and $24 \%$ as other metro regions. The remaining $63 \%$ are divided as follows: $19 \%$ are non-metropolitan regions with access to a metro, $15 \%$ are nonmetropolitan regions with access to a small/medium city, and $29 \%$ are remote regions. Annex B contains results for alternative size and share of population thresholds to show the sensitivity of the results.

The remainder of the paper is organised as follows. Section 2 provides the methodological details and the data sources used. Section 3 presents the results of the classification applied to all OECD TL3 regions where data was available. The section also compares results with those of the already existing and complementary OECD urban-rural classification. Section 4 provides some concluding remarks and identify potential future work to characterise different geographical units across OECD countries.

\footnotetext{
${ }^{2}$ Note that in older OECD studies, metropolitan areas were defined as FUAs with at least half a million inhabitants.

${ }^{3}$ https://ec.europa.eu/eurostat/web/metropolitan-regions/background.
} 


\section{Box 1. The OECD urban-rural typology}

The OECD urban-rural typology was first established in the early 1990s as a result of work for the Rural Indicators Project of the OECD Rural Development Programme. It classifies TL3 regions as "predominantly urban", "intermediate", and "predominantly rural". This typology is based on three criteria:

1. Identify rural local unit ${ }^{4}$ according to population density. A local unit is defined as rural if its population density is below 150 inhabitants per $\mathrm{km}^{2}$ (500 inhabitants for Japan and Korea to account for the fact that the national population density exceeds 300 inhabitants per $\mathrm{km}^{2}$ ).

2. Classify regions according to the percentage of population living in rural local unit. A TL3 region is classified as predominantly rural if more than $50 \%$ of its population lives in rural local unit. TL3 regions are classified as predominantly urban if less than $15 \%$ of the population lives in rural local units. If the share of population in rural local unit is between $15 \%$ and $50 \%$, it is categorised as intermediate.

3. Classify regions based on the size of the urban centres. Accordingly, a region classified as rural on the aforementioned basis becomes intermediate if it has an urban centre of more than 200 thousand inhabitants (500 thousand for Japan) representing no less than $25 \%$ of the regional population. A TL3 region classified as intermediate on the aforementioned basis is classified as predominantly urban if it has an urban centre of more than 500 thousand inhabitants ( 1 million for Japan) representing no less than $25 \%$ of the regional population.

The extended OECD typology developed in 2011 sub-divides rural TL3 regions further into two sub-categories, rural close to cities and rural remote, by adding a distance criterion to urban centres according to a driving time threshold of 1 hour by car ( 45 minutes for North America) to the nearest population agglomeration of 50 thousand inhabitants. Figure A.1 in Annex A summarizes the method.

In Europe, TL3 regions are consistent with the NUTS3 classification adopted by Eurostat. TL3 regions are classified following the European Union (EU) grid-based regional urbanrural typology (Dijkstra and Poelman, 2014 ${ }_{[3]}$ ). This typology included in the 5th Cohesion Report and the 2010 Eurostat Regional Yearbook (see https://ec.europa.eu/eurostat/web/products-statistical-books/-/KS-HA-10-001) was approved in 2010. The EU typology uses $1 \mathrm{~km}^{2}$ population grids as building blocks to identify urban settlements, with the aim of improving international comparability.

To classify TL3 regions, it first distributes local population based on the degree of buildup at the $1 \mathrm{~km}^{2}$ grid-cell level. It then determines the existence of urban clusters based on density levels and cell contiguity, requiring at least 300 people per grid cell and a minimum population of 5 thousand people in each urban cluster. In the last step, it classifies TL3 regions into rural based if $50 \%$ of the population is in rural grid cells; urban if $80 \%$ of the population is in urban clusters, and intermediate otherwise. Rural and intermediate TL3 regions are further classified into close or remote based on driving time by car to a city.

In 2018, there were 389 TL2 and 2,251 TL3 regions across OECD countries.

Source: Brezzi, M., L. Dijkstra and V. Ruiz (2011), “OECD Extended Regional Typology: The Economic Performance of Remote Rural Regions”, OECD Regional Development Working Papers, No. 2011/6, OECD Publishing, Paris, http://dx.doi.org/10.1787/5kg6z83tw7f4-en.; https://ec.europa.eu/eurostat/statistics-explained/index.php/Regional_typologies_overview\#Urbanrural_typology_including_remoteness. 


\section{Box 2. Methodology to delineate Functional Urban Areas}

FUAs consist of densely populated cities and of adjacent local units with high levels of commuting (travel-to-work flows) towards the densely populated cities. FUAs are created using gridded data, thereby not relying on administrative boundaries. The method starts from the identification of urban centres through the population grid. An urban centre is a cluster of contiguous grid cells having at least 1500 inhabitants per $\mathrm{km}^{2}$ and a total population of at least 50000 inhabitants.

The methodology to delineate FUAs consists of three main steps:

1. Identification of cities: Population grid data (either official ones provided by NSOs or publicly available estimated ones, such as the Global Human Settlement Layer) at $1 \mathrm{~km}^{2}$ are used to define urban centres. Subsequently, urban centres are adapted to the local (administrative or statistical) units (i.e. municipalities) for which commuting data is available. The "city" or "core" is made up of contiguous units that have more than $50 \%$ of their populations living within an urban centre.

2. Identification of interconnected cities that are part of the same functional urban area: Two cities are considered as being part of the same FUA if more than $15 \%$ of the population of any of the two cities commutes to work to the other city. In countries where commuting distances are increasing, large urban areas are developing in a polycentric way, hosting highly densely inhabited cores that are physically separated but economically integrated.

3. Definition of the commuting zones surrounding cities: The commuting zone of the FUA groups the surrounding local units that are linked to cities by the commuting pattern of their workforce. Any municipality with at least $15 \%$ of its employed residents working in a certain urban core is considered part of the same FUA.

FUAs are defined for all OECD countries, with the exception of Israel, New Zealand or Turkey due to a lack of commuting data. Across OECD countries, there are a total of 1130 FUAs. Overall, 69\% of the total population in 33 OECD countries lived in FUAs in 2015.

Source: OECD (2012), Redefining "Urban": A New Way to Measure Metropolitan Areas, OECD Publishing, Paris, http://dx.doi.org/10.1787/9789264174108-en.

\footnotetext{
${ }^{4}$ A local unit is an administratively or legally defined unit considered as the smallest building block for the classification. In most countries, local units correspond to municipalities. Being administrative entities, the average size of local administrative unit can change significantly across countries.
} 


\section{New proposed classification of TL3 Regions based on FUA boundaries}

The method presented in this paper classifies TL3 regions into metropolitan and nonmetropolitan according to the following criteria (Figure 1):

- Metropolitan TL3 region (MR), if more than 50\% of its population lives in a FUA of at least 250 thousand inhabitants. MRs are further classified according to their level of access to FUAs of different sizes into:

- Large metro TL3 region (MR-L), if more than 50\% of its population lives in a FUA of at least 1.5 million inhabitants.

- Metro TL3 region (MR-M), if the TL3 region is not a large metro region and $50 \%$ of its population lives in a FUA of at least 250 thousand inhabitants.

- Non-metropolitan TL3 region (NMR), if less than 50\% of its population lives in a FUA. NMRs are further classified according to their level of access to FUAs of different sizes into:

- With access to a metro TL3 region (NMR-M), if more than $50 \%$ of its population lives within a 60 minute drive from a metro (a FUA with more than 250 thousand people); or if the TL3 region contains more than $80 \%$ of the area of a FUA of at least 250 thousand inhabitants.

- With access to a small/medium city TL3 region (NMR-S), if the TL3 region does not have access to a metro and $50 \%$ of its population has access to a small or medium city (a FUA of more than 50 thousand and less than 250 thousand inhabitants) within a 60 minute drive; or if the TL3 region contains more than $80 \%$ of the area of a small or medium city.

- Remote TL3 region (NMR-R), if the TL3 region is not classified as NMR-M or NMR-S, i.e. if $50 \%$ of its population does not have access to any FUA within a 60 minute drive. 
Figure 1. Summary of TL3 typology criteria

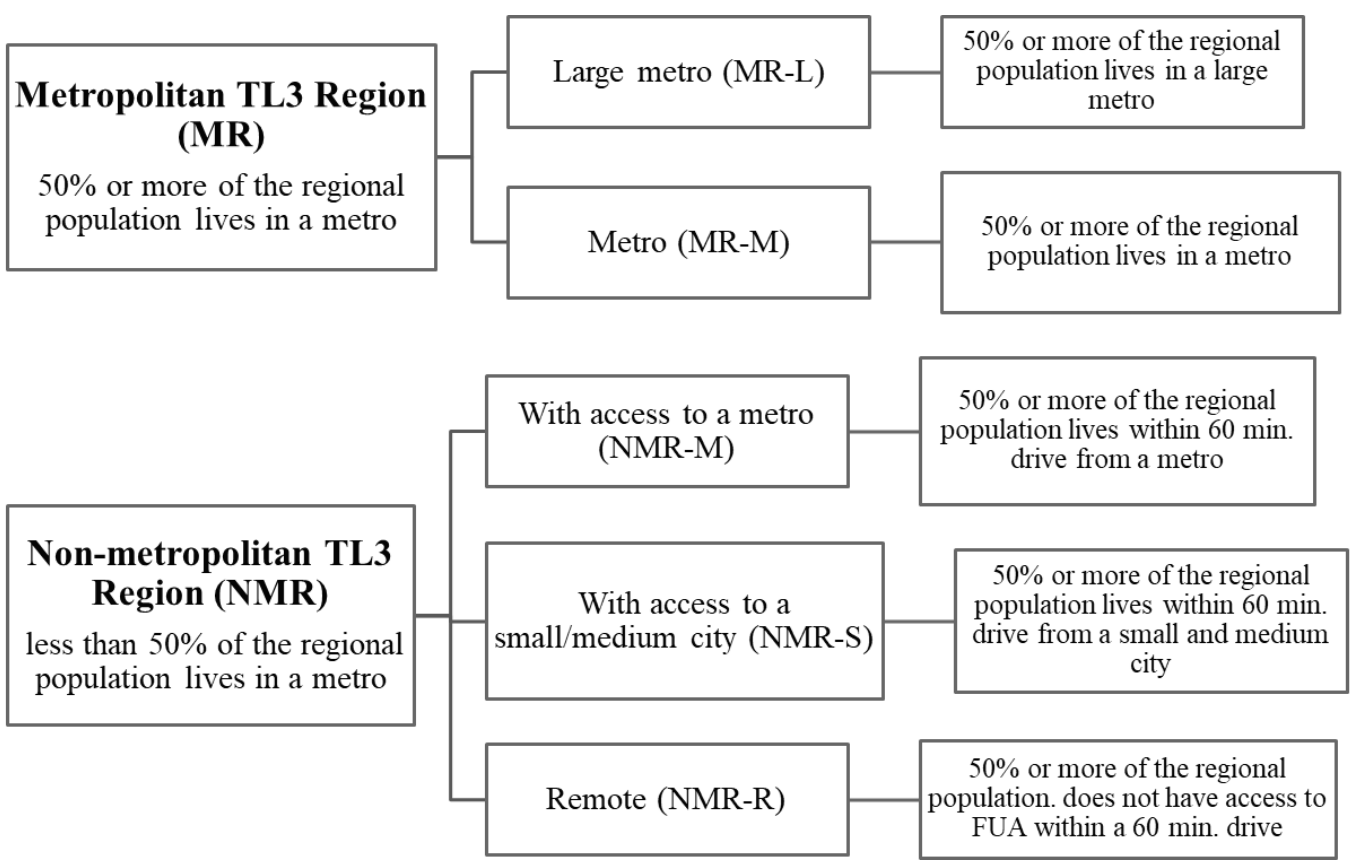

Note: Metro: FUA with population larger than 250K; Large metro: FUA with population larger than 1.5 million; Small/medium city: FUA with population smaller or equal to $250 \mathrm{~K}$.

The threshold of 250 thousand inhabitants is consistent with the threshold used by Eurostat in their classification of metropolitan regions. ${ }^{5}$ It is also compatible with the United States definition of Major and Medium Metro Cores that include core urban counties of metropolitan areas with at least 250 thousand inhabitants.

The concept of level of access is not confined to national boundaries, thereby providing an internationally comparable measure based on accessibility. Indeed, TL3 regions can potentially be categorized as with access to a metro or a small city even if there are no FUAs close to the region in the same country. For example, the French TL3 region of Savoie is classified as non-metro with access to a metro because it is within a 60-minute drive from the FUA of Geneva in Switzerland.

The following paragraphs explain in details all the steps that should be follow to apply the classification method. The first step classifies each TL3 region as metro or non-metro. The second step creates a drive-time polygon around the FUA, i.e. a polygon showing the distance that a person could cover if they were to drive for 60 minutes from a given point. The third and final step estimates the population in each TL3 region that lives in the polygon created in the second step and estimates the area of a FUA that is contained in each TL3 region. Figure 2 provides a visual summary of all steps of the method. Such steps are explained in more detail below.

\footnotetext{
5 The classification can be found at: https://ec.europa.eu/eurostat/documents/4313761/4311719/Metropolitan-region-typology-NUTS2013.xlsx (Last accessed: March 2019).
} 
Figure 2. Categorization process for TL3 regions

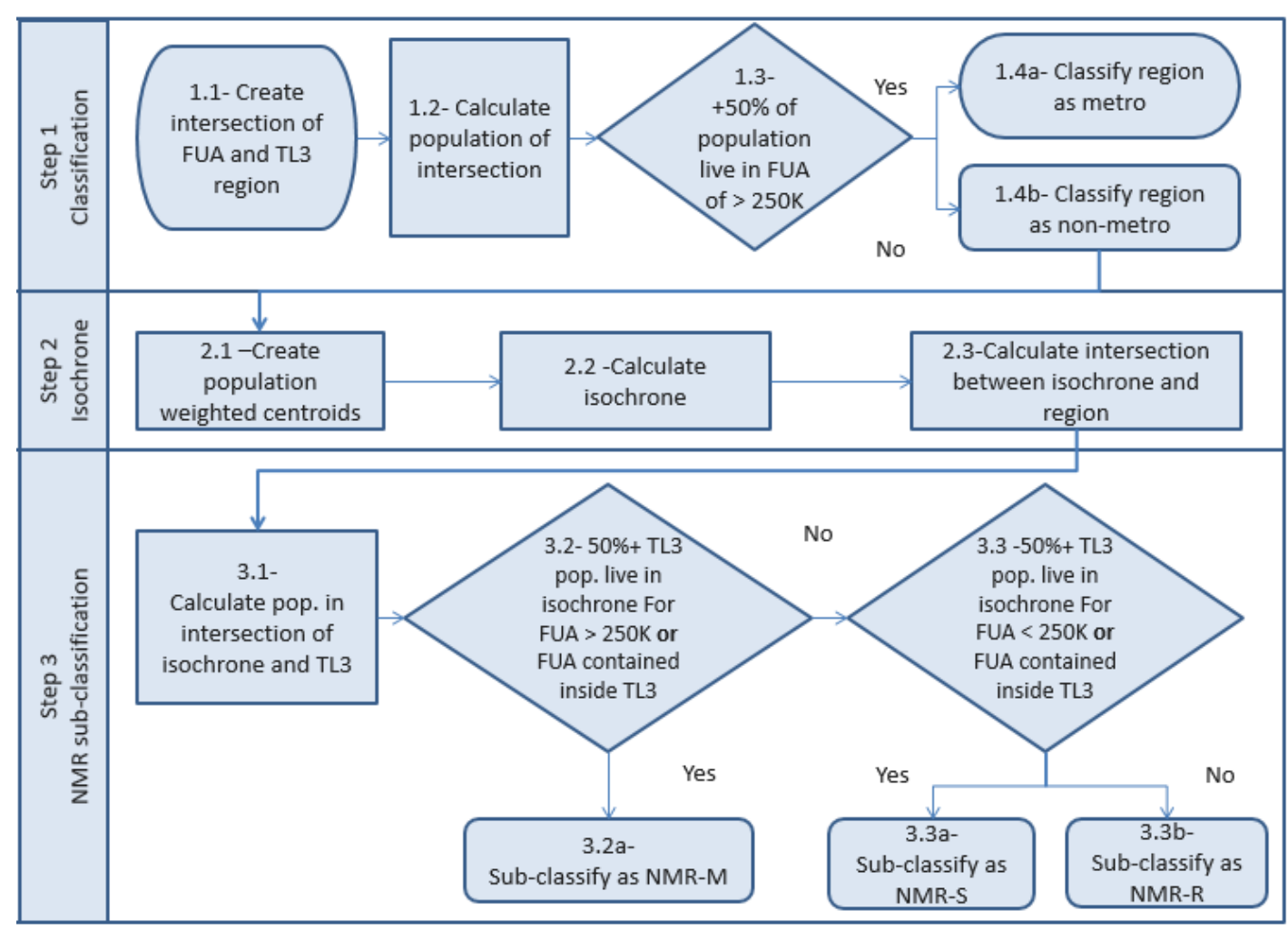

\section{Step 1-Classifying TL3 regions as metropolitan or non-metropolitan}

The method to classify TL3 regions is based on the share of population of each region living in a metropolitan area. To do this, it is first necessary to determine the area of overlap of each TL3 region and a metropolitan area (Figure 3). Second, it is necessary to determine the number of people that live in the overlap and calculate the population of the entire TL3 region. These steps make it possible to determine the share of population of a TL3 region that live inside a metropolitan area. ${ }^{6}$ In cases where this proportion is greater than $50 \%$, the TL3 region is classified as a metro region (MR). In all other cases, the TL3 region is classified as a non-metro region (NMR).

\footnotetext{
${ }^{6}$ If a TL3 region is completely included in a FUA, then this percent will be $100 \%$. For areas that partially overlap, this number will depend on how the population is distributed. For the TL3 regions of Zuidwest-Friesland (Netherlands), Overig Zeeland (Netherlands), Södermanland County (Sweden), and those intersecting the FUA of Reykjavík, Iceland, the source for population comes from administrative sources and not the population grid.
} 
Figure 3. Intersection of FUA and TL3

The figure shows the overlap between the FUA of Toulouse, France (shaded) and the TL3 regions.

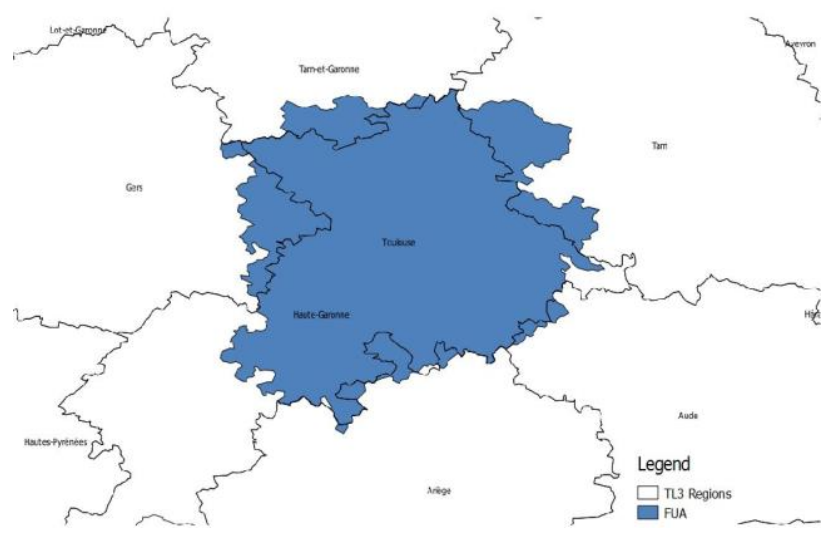

Source: OECD TL3 and FUA boundaries,

http://www.oecd.org/cfe/regional-policy/functionalurbanareasbycountry.

Population shares are calculated using high resolution population grids. For European countries, the source used was the GEOSTAT grid available for the year 2011 at a resolution of $1-\mathrm{km}^{2}$ (Eurostat, 2011 $\left.1_{[4]}\right)$. For non-European countries, the source was the GHS population grid for the year 2015 available at a resolution of $250 \times 250 \mathrm{~m}^{2}$. The GHS grid has a resolution of $1-\mathrm{km}^{2}$ and consists of estimates of population where people is attributed to cells based on built-up areas (Freire et al., 2016 $\left.{ }_{[5]}\right){ }^{7}$

\section{Step 2-Create a drive-time polygon}

The sub-classification of non-metropolitan regions is based on a drive-time polygon, also known as an isochrone. A drive-time polygon provides a measure of the distance covered by driving for a determined period of time from a given point by car. This measure takes into account the road infrastructure, local speed limits and natural boundaries. Drive-time polygons were created using data from Open Street Map (OSM) ${ }^{8}$ Figure 4 shows an example for the FUA of Oostende, Belgium.

\footnotetext{
${ }^{7}$ The GHS and GEOSTAT data are available at the following links:

https://ghsl.jrc.ec.europa.eu/ghs_pop.php;

https://ec.europa.eu/eurostat/web/gisco/geodata/reference-data/population-distribution-demography/geostat

${ }^{8}$ To calculate the drive-time polygon, the OSRM R package was used (R Core Team, $\left.2018_{[8]}\right)$.
} 
Figure 4. Drive-time polygon (isochrone)

The figure shows a drive-time polygon (isochrone) for the FUA of Oostende, Belgium. It shows the distance covered by driving 45 and 60 minutes from the population weighted centroid of the FUA.

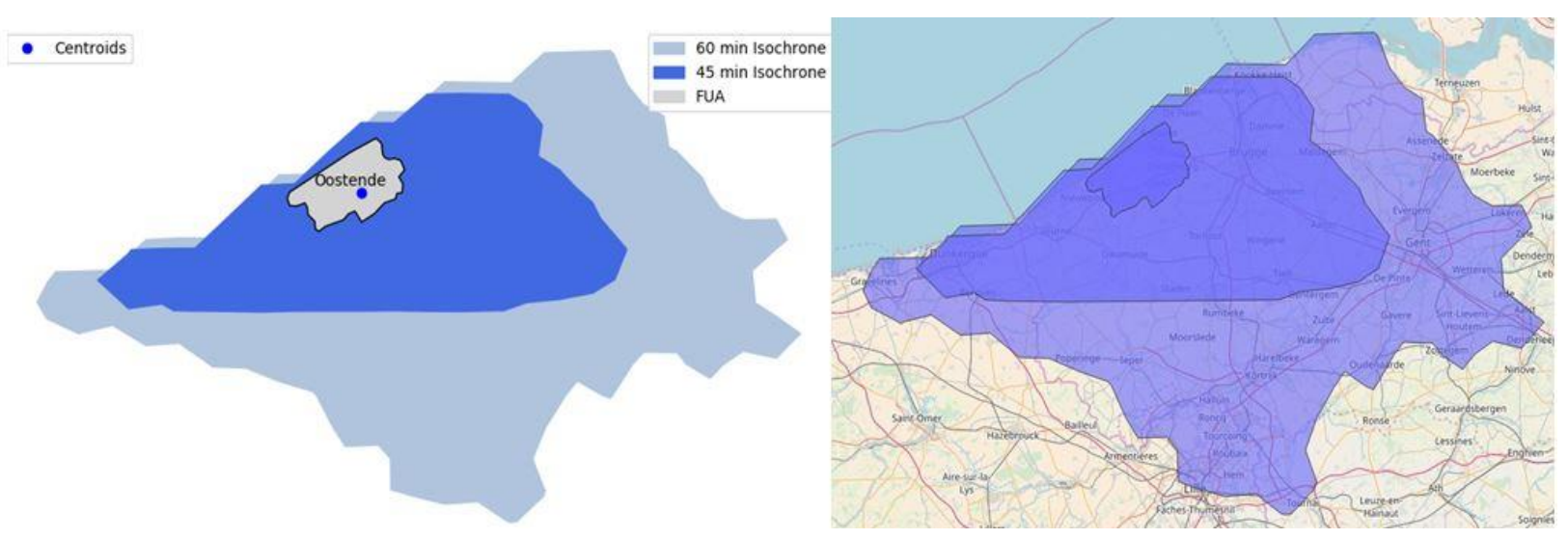

Source: Open Street Maps.

The steps required to build a drive-time radius are:

- Select a geographic point of reference. The point must be a coordinate with a latitude and longitude. For this exercise the population weighted centroid of the core of each FUA is used as the point of reference. ${ }^{9}$

Use the point of reference to calculate the distance (on any direction) that a person could travel under ideal driving conditions.

Calculate the area of intersection between the drive-time polygon and the TL3 region.

\section{Step 3- Sub-classifying metropolitan and non-metropolitan TL3 regions}

After creating drive-time polygons, the next step is to examine the percentage of the population within each TL3 region that lives inside the polygon. Finally, the last step is to determine if the FUA is located in the TL3 region. This is done by calculating the percent of a FUA's area that is located within a TL3 region's boundaries.

Metropolitan TL3 regions are sub-classified into large metro and metro regions.

- Large metro TL3 region (MR-L), if more than 50\% of its population lives in a FUA of at least 1.5 million inhabitants.

- Metro TL3 region (MR-M), if the region is not a large metro TL3 region and 50\% of its population lives in a FUA of at least 250 thousand inhabitants.

\footnotetext{
${ }^{9}$ A population weighted centroid is the weighted average of points in a given polygon. In cases where the centroids are located outside of the polygon, the centroid is placed inside the polygon using the closest Euclidean distance.
} 
Non-metropolitan TL3 regions are classified as:

With access to a metro TL3 region (NMR-M), if more than 50\% of its population lives within a 60-minute drive of a metropolitan area; or if the TL3 region contains more than $80 \%$ of the area of a FUA of at least 250 thousand inhabitants. ${ }^{10}$

With access to a small/medium city TL3 region (NMR-S), if the TL3 region is not a NMR-M TL3 region and more than $50 \%$ of its population lives within a 60 minute drive of a functional urban area of less than 250 thousand people; or if the TL3 region contains more than $80 \%$ of the area of a FUA of less than 250 thousand inhabitants.

Remote TL3 region (NM-R), if the region is not a NMR-M or a NMR-S region.

${ }^{10}$ The $80 \%$ rule is applied to avoid the situation where an FUA covers most of the territory of a TL3 and yet the region is classified as remote. This rule only affects less than half of one percent of the population across OECD countries. 


\section{Results}

Table 1 summarizes the results and Figures 4-6 contain maps of the resulting classification by regions of the world. Across OECD countries, $71 \%$ of the population lives in metropolitan TL3 regions (MR), out of which $42 \%$ lives in large metro regions (MR-L) and $29 \%$ in metro regions (MR-M). Of the remaining $29 \%$ of people that live in nonmetropolitan regions (NMR), $12 \%$ live in regions close to a metro (NMR-M), $9 \%$ in regions close to a small/medium city (NMR-S), and $8 \%$ in remote regions (NMR-R) (Table 1). All OECD countries, with the exception of Iceland, have at least one metropolitan TL3 region that is classified as MR.

The results confirm there is no one-to-one correspondence between the rural-urban and proposed typologies, although there is considerable overlap in predominantly urban and metropolitan regions and between predominantly rural and non-metropolitan regions. While 402 out of 502 urban regions were classified as metropolitan, 849 out of 990 rural regions were classified as non-metropolitan. The proposed typology reallocates 657 intermediate regions into 254 metropolitan and 403 non-metropolitan regions.

The countries with the highest share of population living in metropolitan regions are: Luxemburg $(100 \%)^{11}$, Korea $(89 \%)$, the United States (84\%), Australia (70\%), and Germany (68\%). Conversely, the lowest rates occur in Slovakia (25\%), Switzerland (50\%), and Slovenia (41\%). Geographically, the share of people in European countries that live in metropolitan regions (59\%) is 20 percentage points lower than in non-European countries in the OECD (79\%). While the results highlight a spatial concentration of population within specific TL3 regions across OECD countries, some countries have a significant share of population living in non-metropolitan remote regions such as Norway (34\%) and Estonia (21\%).

Regarding the total number of regions, 37\% of OECD TL3 regions are classified as metropolitan, out of which $13 \%$ are sub-classified as large (MR-L) and 24\% as metro (MR$\mathrm{M})$. The remaining $63 \%$ are non-metropolitan and are distributed as follows: $19 \%$ are close to a metro (NMR-M), $15 \%$ are close to a small/medium city (NMR-S), and $29 \%$ are remote (NMR-R). In Japan and Korea, over 65\% of all TL3 regions are metropolitan regions, while in the United States, Great Britain, and Denmark and Germany the share is over 50\%. On the contrary, in countries such as Canada, Greece, and Norway over 50\% of regions are classified as non-metropolitan remote regions.

To check the sensitivity of the classification to changes in population and driving-time thresholds, Annex B presents a sensitivity analysis showing results obtained by defining a metropolitan area as a FUA of at least 100 and 500 thousand inhabitants (instead of 250 thousand) and using drive-time polygons of 45 and 60 minutes. Using the threshold of 500 thousand with a 60-minute drive-time threshold lowers the percent of population in the OECD living in a metro TL3 region from $70 \%$ to $61 \%$.

\footnotetext{
${ }^{11}$ Luxemburg only has one TL3 region.
} 
Table 1. Distribution of population and number of TL3 regions by category, 2015

Metro areas > 250000 inhabitants; 60-minute drive time.

\begin{tabular}{|c|c|c|c|c|c|c|c|c|c|c|}
\hline \multirow{3}{*}{ Country } & \multicolumn{5}{|c|}{ Population Living in TL3 Regions (\%) } & \multicolumn{5}{|c|}{ Number of TL3 Regions } \\
\hline & \multicolumn{2}{|c|}{ Metropolitan Regions } & \multicolumn{3}{|c|}{ Non-metropolitan Regions } & \multicolumn{2}{|c|}{ Metropolitan Regions } & \multicolumn{3}{|c|}{ Non-metropolitan Regions } \\
\hline & $\begin{array}{l}\text { Large (MR- } \\
\text { L) }\end{array}$ & $\begin{array}{c}\text { Metro (MR- } \\
\text { M) }\end{array}$ & $\begin{array}{l}\text { Metro } \\
\text { (NM-M) }\end{array}$ & $\begin{array}{l}\text { Small and } \\
\text { Medium } \\
\text { (NM-S) }\end{array}$ & $\begin{array}{l}\text { Remote } \\
\text { (NM-R) }\end{array}$ & $\begin{array}{l}\text { Large } \\
\text { (MR-L) }\end{array}$ & $\begin{array}{l}\text { Metro } \\
\text { (MR-M) }\end{array}$ & $\begin{array}{l}\text { Metro } \\
\text { (NM-M) }\end{array}$ & $\begin{array}{c}\text { Small and } \\
\text { Medium } \\
\text { (NM-S) }\end{array}$ & $\begin{array}{l}\text { Remote } \\
\text { (NM-R) }\end{array}$ \\
\hline AUS & 56.8 & 13.8 & 1.1 & 7.0 & 21.3 & 4 & 6 & 1 & 8 & 31 \\
\hline AUT & 31.3 & 23.5 & 21.1 & 12.0 & 12.1 & 5 & 6 & 8 & 7 & 9 \\
\hline BEL & 22.4 & 23.8 & 50.9 & 2.5 & 0.4 & 4 & 6 & 29 & 4 & 1 \\
\hline CAN & 43.4 & 22.5 & 6.1 & 3.9 & 24.1 & 28 & 31 & 20 & 14 & 200 \\
\hline CHE & 0.0 & 50.3 & 24.6 & 18.6 & 6.5 & 0 & 6 & 8 & 9 & 3 \\
\hline $\mathrm{CHL}$ & 40.5 & 29.8 & 2.4 & 20.4 & 6.8 & 5 & 9 & 2 & 16 & 22 \\
\hline CZE & 24.6 & 32.3 & 0.0 & 43.1 & 0.0 & 2 & 4 & 0 & 8 & 0 \\
\hline DEU & 30.7 & 37.0 & 23.1 & 5.8 & 3.4 & 62 & 145 & 130 & 34 & 31 \\
\hline DNK & 35.4 & 33.4 & 30.4 & 0.0 & 0.7 & 4 & 3 & 3 & 0 & 1 \\
\hline ESP & 35.1 & 33.8 & 8.3 & 20.8 & 2.0 & 4 & 16 & 6 & 23 & 10 \\
\hline EST & 0.0 & 42.6 & 0.0 & 36.3 & 21.1 & 0 & 1 & 0 & 2 & 2 \\
\hline FIN & 0.0 & 46.1 & 3.3 & 20.9 & 29.7 & 0 & 3 & 1 & 4 & 11 \\
\hline FRA & 25.8 & 40.2 & 11.6 & 12.4 & 10.0 & 10 & 31 & 17 & 19 & 24 \\
\hline GBR & 35.4 & 32.5 & 22.4 & 4.0 & 5.7 & 50 & 52 & 44 & 7 & 20 \\
\hline GRC & 39.6 & 9.6 & 0.0 & 22.4 & 28.5 & 7 & 1 & 0 & 13 & 31 \\
\hline HUN & 30.2 & 20.3 & 11.1 & 36.3 & 2.1 & 2 & 4 & 3 & 10 & 1 \\
\hline IRL & 39.4 & 14.2 & 0.0 & 28.6 & 17.8 & 2 & 1 & 0 & 3 & 2 \\
\hline ISL & 0.0 & 0.0 & 0.0 & 86.4 & 13.6 & 0 & 0 & 0 & 4 & 4 \\
\hline ITA & 22.5 & 24.1 & 22.9 & 25.3 & 5.1 & 6 & 17 & 30 & 42 & 15 \\
\hline JPN & 54.8 & 29.6 & 14.6 & 0.4 & 0.5 & 11 & 21 & 13 & 1 & 1 \\
\hline KOR & 68.3 & 21.2 & 7.4 & 3.1 & 0.0 & 7 & 6 & 3 & 1 & 0 \\
\hline LTU & 0.0 & 46.5 & 0.0 & 34.5 & 19.1 & 0 & 2 & 0 & 4 & 4 \\
\hline LUX & 0.0 & 100.0 & 0.0 & 0.0 & 0.0 & 0 & 1 & 0 & 0 & 0 \\
\hline LVA & 0.0 & 31.0 & 0.0 & 58.7 & 10.3 & 0 & 1 & 0 & 4 & 1 \\
\hline MEX & 34.1 & 30.8 & 10.4 & 5.5 & 19.3 & 14 & 49 & 28 & 17 & 101 \\
\hline NLD & 21.7 & 31.7 & 25.6 & 21.0 & 0.0 & 6 & 8 & 16 & 10 & 0 \\
\hline NOR & 0.0 & 42.4 & 16.8 & 6.6 & 34.1 & 0 & 4 & 3 & 2 & 10 \\
\hline POL & 16.1 & 33.6 & 12.7 & 28.3 & 9.3 & 8 & 21 & 10 & 24 & 9 \\
\hline PRT & 26.3 & 21.1 & 20.8 & 16.5 & 15.3 & 1 & 2 & 6 & 6 & 10 \\
\hline SVK & 0.0 & 25.8 & 10.3 & 63.9 & 0.0 & 0 & 2 & 1 & 5 & 0 \\
\hline SVN & 0.0 & 40.6 & 40.5 & 11.6 & 7.3 & 0 & 2 & 6 & 2 & 2 \\
\hline SWE & 22.2 & 33.5 & 2.9 & 16.5 & 24.9 & 1 & 3 & 1 & 5 & 11 \\
\hline USA & 59.2 & 25.0 & 6.6 & 2.4 & 6.9 & 31 & 59 & 18 & 15 & 56 \\
\hline OECD & 41.9 & 28.9 & 12.3 & 8.8 & 8.1 & 274 & 523 & 407 & 323 & 623 \\
\hline
\end{tabular}

Source of population data: GHS population grid. https://ghsl.jrc.ec.europa.eu/ghs_pop.php. 
Figure 4. Categorization of TL3 regions: North America and Chile

Metro areas > 250000 inhabitants; 60-minute drive time.

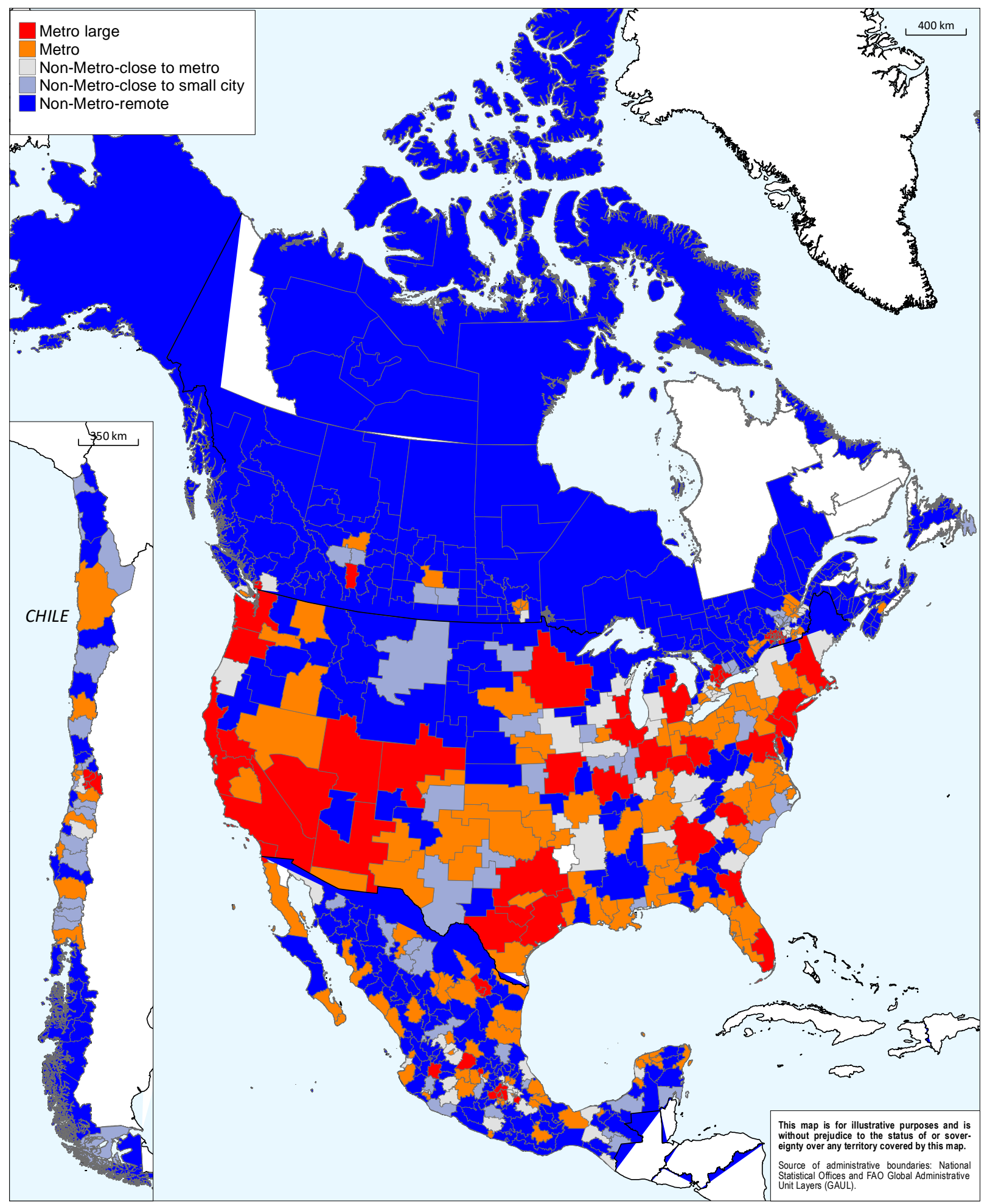


Figure 5. Categorization of TL3 regions: Europe

Metro areas > 250000 inhabitants; 60-minute drive time.

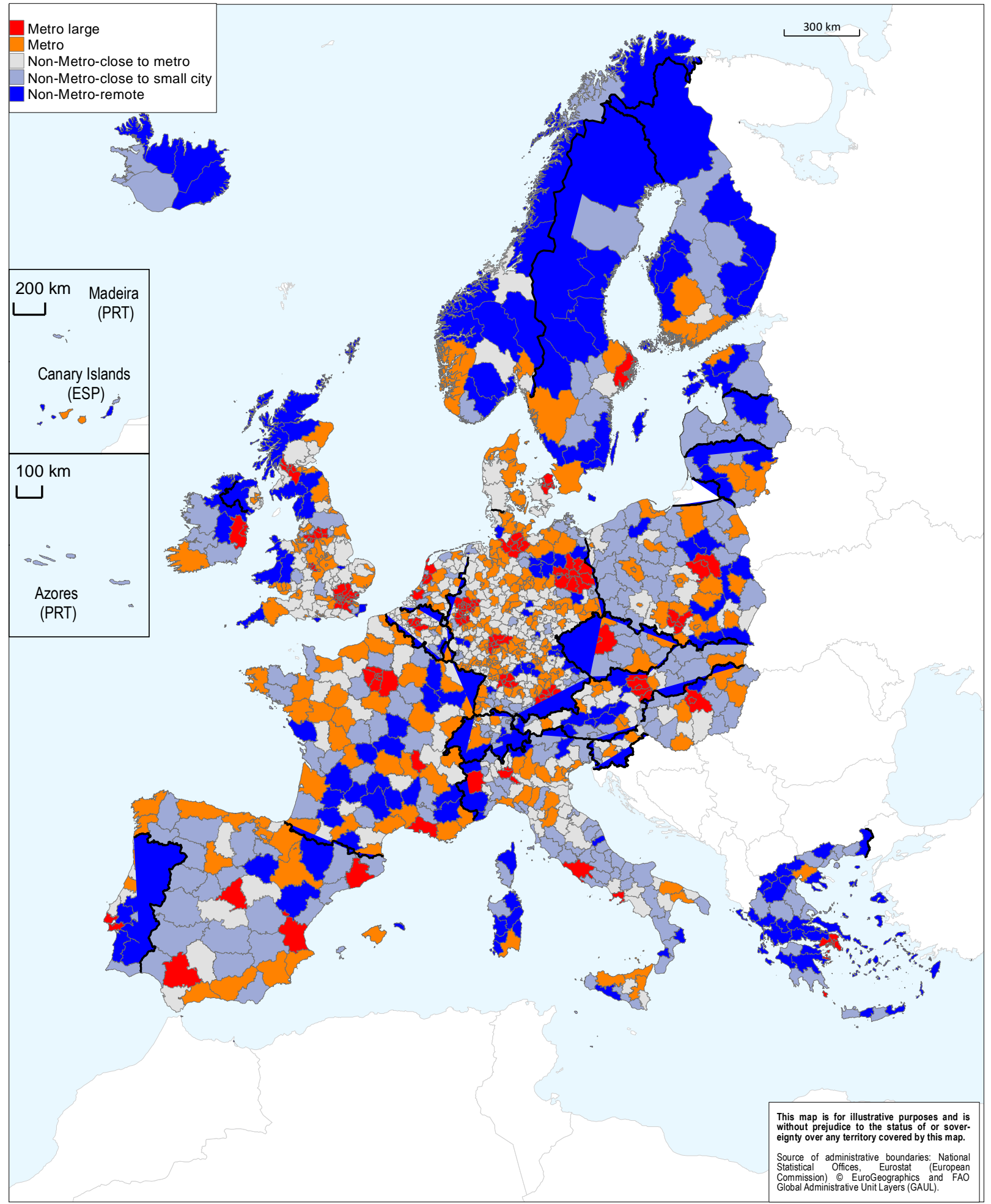


Figure 6. Categorization of TL3 regions- Asia and Oceania

Metro areas > 250000 inhabitants; 60-minute drive time.

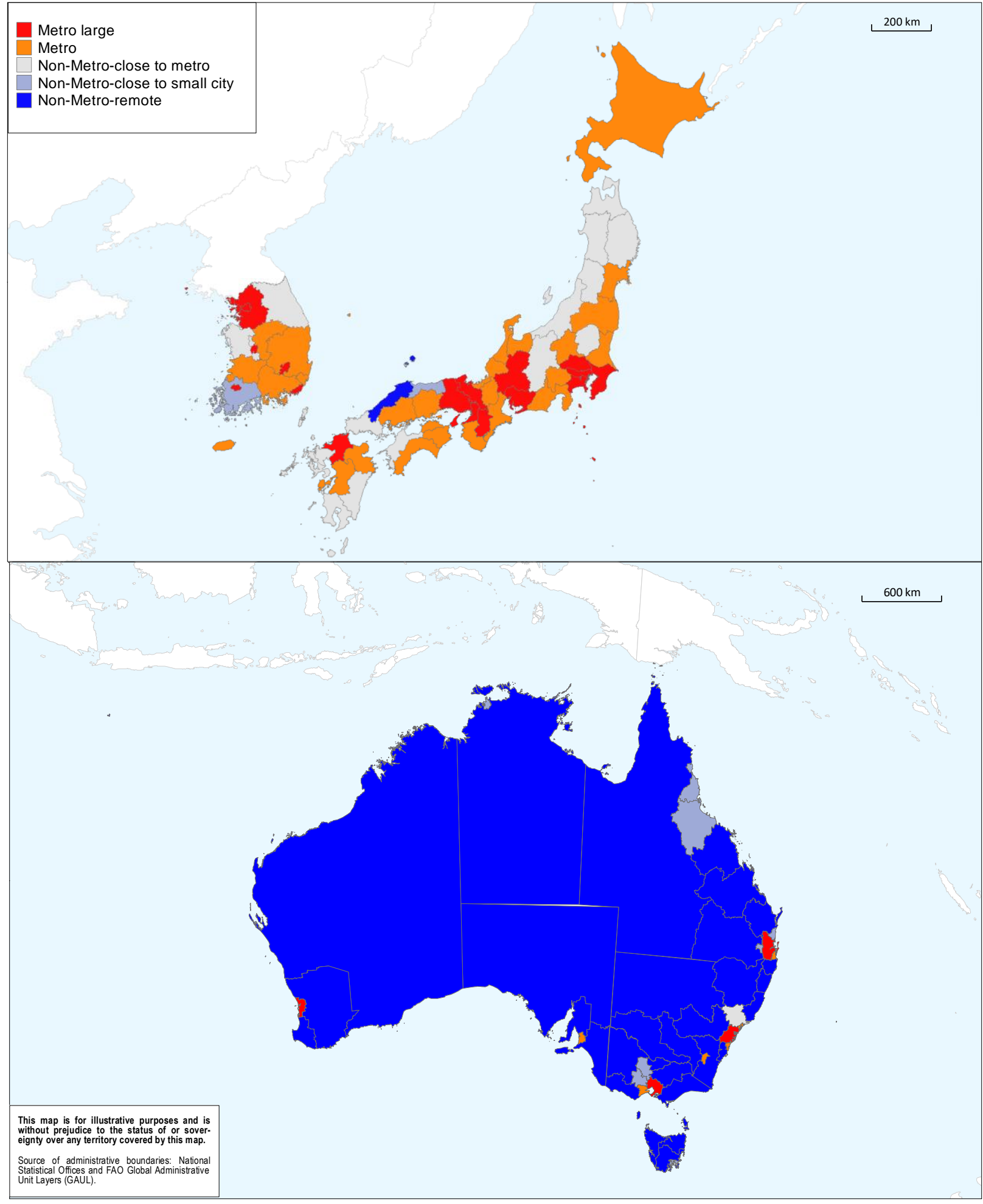


The difference between the classification proposed in this paper and the OECD TL3 urbanrural typology consists of three main points (see Table 2).

First, the method presented in this paper classifies TL3 regions in terms of their level of access to dense markets instead of density levels. In contrast, the urban-rural typology depends on population density and on city size only to re-classify a PR as "Intermediate" when such a region contains an urban centre of at least 200 thousand people. For the EU grid-based rural-urban typology, the classification depends on population density (determined at the $1-\mathrm{km}^{2}$ grid cell level) and urban population size, including both urban centres (made up of contiguous cells with a density of 300 people or more each and a total population of 50 thousand people or more) and/or urban clusters (Eurostat, 2013).

Second, the two methods rely on different thresholds, which are in turn measured at different scales. This implies that there is no one-to-one correspondence between any of the categories of the two methodologies. In fact, TL3 regions in the Intermediate category are split between Metropolitan and Non-metropolitan TL3 regions, while a strong correlation can be expected between the classification of predominantly urban and metropolitan region on the one hand, and of predominantly rural and non-metropolitan on the other. The reason is that although urban regions that contain a FUA of 250 thousand people will all be classified as metropolitan, there can be urban regions with small/medium FUAs that will be classified as non-metropolitan as they fail to meet the 250 thousand threshold. On the other hand, rural regions that have access to a large FUA and/or contain part of commuting zones will be classified as metropolitan.

Lastly, although both methodologies use a similar distance threshold, the role of access to an urban core in determining the categories only matters for predominantly rural regions in the urban-rural typology, while it cuts across all categories in the proposed methodology. Furthermore, the method presented in this paper makes a distinction between access to urban areas of different sizes; while the urban-rural typology does not distinguish between access from a remote region to a large or a small city. This distinction can prove useful in settings where the focus is on rural-urban linkages and the role of market access, as the question in this case is not only whether regions have access, but to what type of markets they have access to. 
Table 2. Comparison OECD TL3 urban-rural typology and proposed classification

\begin{tabular}{|c|c|c|c|c|c|c|}
\hline & \multicolumn{2}{|c|}{ Categories } & \multicolumn{2}{|c|}{ First tier } & \multicolumn{2}{|c|}{ Second tier } \\
\hline & First tier & Second tier & Determinants & Thresholds & Determinants & Thresholds \\
\hline $\begin{array}{l}\text { OECD } \\
\text { TL3 } \\
\text { urban- } \\
\text { rural }\end{array}$ & $\begin{array}{l}3 \text { categories: } \\
\text { Predominantly } \\
\text { Urban (PU); } \\
\text { Intermediate } \\
\text { (IN); } \\
\text { Predominantly } \\
\text { Rural (PR). }\end{array}$ & $\begin{array}{l}2 \text { categories (of } \\
\text { PR): Close and } \\
\text { Remote. }\end{array}$ & $\begin{array}{l}\text { Population } \\
\text { density; } \\
\text { population size in } \\
\text { the case of PRs } \\
\text { with a city of more } \\
\text { than } 200 \\
\text { thousand people } \\
\text { (adding } 25 \% \text { of } \\
\text { the regional } \\
\text { population or } \\
\text { more). } \\
\text { For EU (grid- } \\
\text { based) urban- } \\
\text { rural typology: } \\
\text { Population } \\
\text { density and } \\
\text { population size. }\end{array}$ & $\begin{array}{l}\text { PR if } 50 \% \text { of } \\
\text { population lives in } \\
\text { rural local units } \\
\text { (areas with density } \\
\text { below } 150 \text { inh...km² } \\
\text { or } 300 \text { for Japan and } \\
\text { Korea); PU if less } \\
\text { than } 15 \% \text { of people } \\
\text { live in rural local } \\
\text { units; IN otherwise. } \\
\text { For EU (grid-based) } \\
\text { urban-rural typology: } \\
\text { PR if } 50 \% \text { of } \\
\text { population lives in } \\
\text { rural grid cells (1 } \\
\text { km² cells with less } \\
\text { than } 300 \text { people); } \\
\text { PU if } 80 \% \text { of } \\
\text { population lives in } \\
\text { urban cluster cells } \\
\text { (contiguous } 1 \text { km² } \\
\text { cells with more than } \\
300 \text { people and at } \\
\text { least } 5000 \text { people); } \\
\text { IN otherwise. }\end{array}$ & $\begin{array}{l}\text { Distance from PR } \\
\text { region to closest } \\
\text { centre of an } \\
\text { urban centre. } \\
\text { For EU (grid- } \\
\text { based) urban- } \\
\text { rural typology: } \\
\text { Distance from a } \\
\text { PR or IN to the } \\
\text { centre of an } \\
\text { urban centre. }\end{array}$ & $\begin{array}{l}60 \text { minute drive (45 } \\
\text { minutes for North } \\
\text { America). } \\
\text { For EU (grid-based) } \\
\text { urban-rural typology: } 45 \\
\text { minute drive by at least } \\
\text { half of the residents of the } \\
\text { region. }\end{array}$ \\
\hline $\begin{array}{l}\text { New } \\
\text { TL3 } \\
\text { based } \\
\text { on } \\
\text { access } \\
\text { to } \\
\text { FUAs }\end{array}$ & $\begin{array}{l}2 \text { categories: } \\
\text { Metropolitan } \\
\text { (MR) and non- } \\
\text { metropolitan } \\
\text { (NMR). }\end{array}$ & $\begin{array}{l}2 \text { categories (of } \\
\text { MR): MR-L = } \\
\text { large } \\
\text { metropolitan } \\
\text { region ; MR-M= } \\
\text { metropolitan } \\
\text { region. } \\
3 \text { categories (of } \\
\text { NMR): NM-M = } \\
\text { With access to a } \\
\text { metro ; NM-S= } \\
\text { with access to } \\
\text { small/medium } \\
\text { city; NM- } \\
\text { R=Remote. }\end{array}$ & $\begin{array}{l}\text { Presence of } \\
\text { urban centre; } \\
\text { Functional ties to } \\
\text { urban centre. }\end{array}$ & $\begin{array}{l}\text { MR if } 50 \% \\
\text { population lives in } \\
\text { FUA of at least } 250 \\
\text { thousand people; } \\
\text { NMR otherwise. }\end{array}$ & $\begin{array}{l}\text { Distance from } \\
\text { centroid of a } \\
\text { (large or } \\
\text { small/medium) } \\
\text { FUA. }\end{array}$ & $\begin{array}{l}\text { MR-L: } 50 \% \text { of regional } \\
\text { population lives in a FUA } \\
\text { of at least } 1.5 \text { million } \\
\text { inhabitants; MR-M: } 50 \% \text { of } \\
\text { regional population lives in } \\
\text { a FUA of at between } 250 \\
\text { thousand and } 1.5 \text { million } \\
\text { inhabitants. } \\
\text { NM-M: } 50 \% \text { of regional } \\
\text { population is within a } 60 \\
\text { minute drive from a FUA } \\
\text { of at least } 250 \text { thousand } \\
\text { inhabitants or if the TL3 } \\
\text { region contains more than } \\
80 \% \text { of the area of a FUA } \\
\text { of more than } 250 \\
\text { thousand inhabitants; NM- } \\
\text { S: } 50 \% \text { of the regional } \\
\text { population has access to } \\
\text { a FUA of less than } 250 \\
\text { thousand inhabitants or if } \\
\text { the TL3 region contains } \\
\text { more than } 80 \% \text { of the } \\
\text { area of a FUA of less than } \\
250 \text { thousand inhabitants; } \\
\text { NM-R otherwise. }\end{array}$ \\
\hline
\end{tabular}




\section{Concluding remarks}

This paper provides a method to classify TL3 regions based on their level of access to functional urban areas of different size. Developing a statistically robust and internationally comparable system of classification of territorial units has been a topic where the OECD has provided guidance and a contribution to the design of regional development policies for over twenty years.

The proposed classification can represent a valuable tool to analyse socio-economic trends across different types of TL3 regions in a consistent way across countries. It also allows the richness of data available at the TL3 level across OECD countries to be linked with the presence of cities of different sizes, taking into account at the same time their economic extent. For example, all socio-economic indicators available in the OECD Regional Database at the TL3 scale could be aggregated by country - or by the entire OECD - using the classification proposed in this paper. This would allow to assess, among many other things, how trends in GDP per capita, population, employment or productivity are different in OECD countries between different types regions. For example, the evolution of the average gap in GDP per capita between metropolitan regions and remote regions in the last twenty years could be consistently documented across countries.

The proposed classification of non-metropolitan areas should not be considered as an attempt to define functional areas outside FUAs. Such complementary definition is part of ongoing work on the definition of Labour Market Areas (Munro, Alasia and Bollman, $2011_{[4]}$ ) and functional economic regions that can provide an additional tool for territorial analyses.

\section{References}

Brezzi, M., L. Dijkstra and V. Ruiz (2011), “OECD Extended Regional Typology: The Economic Performance of Remote Rural Regions", OECD Regional Development Working Papers, No. 2011/6, OECD Publishing, Paris, http://dx.doi.org/10.1787/5kg6z83tw7f4-en.

Dijkstra, L. and H. Poelman (2014), A harmonised definition of cities and rural areas: the new degree of urbanisation Working Papers, http://ec.europa.eu/regional_policy/sources/docgener/work/2014_01_new_urban.pdf (accessed on 9 August 2018).

Eurostat (2013), Eurostat regional yearbook 2013, Publications Office of the European Union, Luxemburg, http://dx.doi.org/10.2785/44451.

Eurostat, J. (2011), GEOSTAT, https://ec.europa.eu/eurostat/web/gisco/geodata/referencedata/population-distribution-demography/geostat. 
Freire, S. et al. (2016), Development of New Open and Free Multi-Temporal Global Population Grids at $250 \mathrm{~m}$ Resolution.

Munro, A., A. Alasia and R. Bollman (n.d.), "Self-contained labour areas: A proposed delineation and classification by degree of rurality", Rural and Small Town Canada Analysis Bulletin, No. Vol. 8, Num. 8, Catalogue no. 21-006-XIE, Statistics Canada, Ottawa.

OECD (2015), The Metropolitan Century: Understanding Urbanisation and its Consequences, OECD Publishing, Paris, http://dx.doi.org/10.1787/9789264228733-en.

OECD (2012), Redefining “Urban”: A New Way to Measure Metropolitan Areas, OECD Publishing, Paris, http://dx.doi.org/10.1787/9789264174108-en.

R Core Team (2018), R: A language and environment for statistical computing., R Foundation [9] for Statistical Computing, Viena, Austra, https://www.R-project.org/. 


\section{Annex A. Decision trees TL3 extended typology and FUA definition}

Figure A.1. Decision tree OECD TL3 extended typology

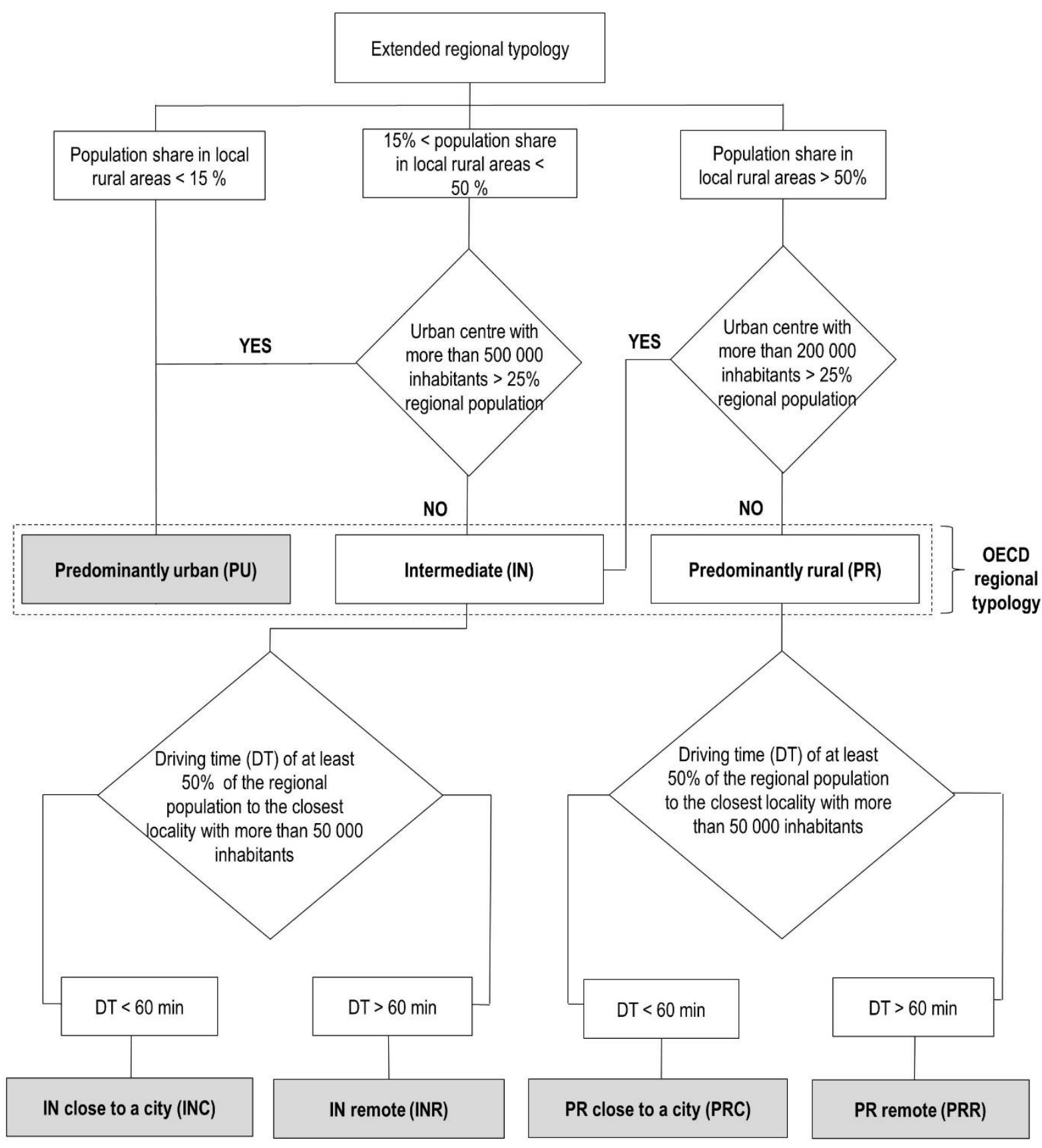

Source: Brezzi et al (2011). 
Figure A.2. Decision tree FUA definition

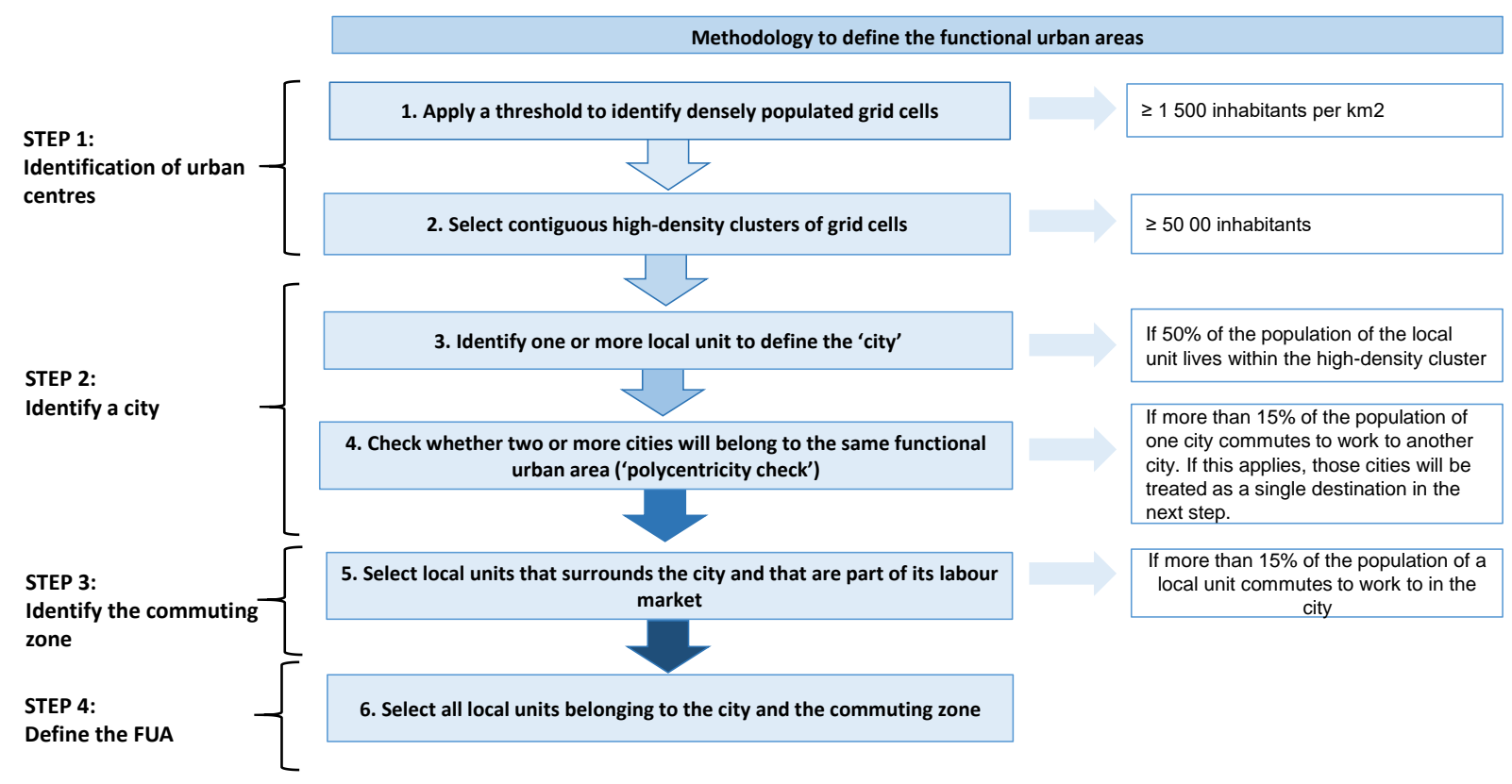

Source: Elaboration based on OECD (2012). 
Annex B. Sensitivity analysis. Classification results with different population and drive time thresholds

Table B.1. 100 thousand inhabitants (metro threshold) with 45 minute drive

\begin{tabular}{|c|c|c|c|c|c|c|c|c|c|c|}
\hline \multirow{3}{*}{ Country } & \multicolumn{5}{|c|}{ Population Living in TL3 Regions } & \multicolumn{5}{|c|}{ Number of TL3 Regions } \\
\hline & \multicolumn{2}{|c|}{ MR } & \multicolumn{2}{|c|}{ NMR } & \multirow[b]{2}{*}{ NM-R $(\%)$} & \multicolumn{2}{|c|}{ MR } & \multicolumn{3}{|c|}{ NMR } \\
\hline & MR-L $(\%)$ & MR-M (\%) & NM-M (\%) & NM-S (\%) & & MR-L & MR-M & NM-M & NM-S & NM-R \\
\hline AUS & 56.8 & 20.8 & 1.1 & 0.0 & 21.3 & 4 & 14 & 1 & 0 & 31 \\
\hline AUT & 31.3 & 24.4 & 9.6 & 0.0 & 34.7 & 5 & 6 & 5 & 0 & 19 \\
\hline BEL & 22.4 & 40.5 & 34.7 & 0.5 & 1.9 & 4 & 13 & 22 & 1 & 4 \\
\hline CAN & 43.4 & 28.6 & 1.4 & 0.0 & 26.6 & 28 & 41 & 10 & 0 & 214 \\
\hline $\mathrm{CHE}$ & 0.0 & 43.8 & 44.4 & 0.0 & 11.8 & 0 & 7 & 12 & 0 & 7 \\
\hline $\mathrm{CHL}$ & 40.5 & 48.5 & 0.0 & 2.7 & 8.3 & 5 & 23 & 0 & 2 & 24 \\
\hline CZE & 24.6 & 28.1 & 44.5 & 2.8 & 0.0 & 2 & 3 & 8 & 1 & 0 \\
\hline DEU & 30.7 & 42.8 & 15.9 & 0.5 & 10.1 & 62 & 177 & 86 & 4 & 73 \\
\hline DNK & 35.4 & 33.4 & 0.0 & 0.0 & 31.2 & 4 & 3 & 0 & 0 & 4 \\
\hline ESP & 35.1 & 37.4 & 24.0 & 1.2 & 2.4 & 4 & 23 & 18 & 3 & 11 \\
\hline EST & 0.0 & 42.6 & 24.9 & 11.5 & 21.1 & 0 & 1 & 1 & 1 & 2 \\
\hline FIN & 0.0 & 67.0 & 0.0 & 0.0 & 33.0 & 0 & 7 & 0 & 0 & 12 \\
\hline FRA & 25.8 & 48.4 & 10.7 & 0.0 & 15.0 & 10 & 44 & 13 & 0 & 34 \\
\hline GBR & 36.5 & 38.8 & 14.5 & 0.0 & 10.2 & 51 & 63 & 28 & 0 & 31 \\
\hline GRC & 38.2 & 21.8 & 1.5 & 9.1 & 29.4 & 6 & 7 & 1 & 6 & 32 \\
\hline HUN & 30.2 & 31.3 & 21.5 & 12.6 & 4.4 & 2 & 8 & 4 & 4 & 2 \\
\hline IRL & 39.4 & 14.2 & 17.7 & 10.8 & 17.8 & 2 & 1 & 2 & 1 & 2 \\
\hline ISL & 0.0 & 86.4 & 0.0 & 0.0 & 13.6 & 0 & 4 & 0 & 0 & 4 \\
\hline ITA & 22.5 & 31.7 & 34.4 & 2.1 & 9.2 & 6 & 33 & 41 & 5 & 25 \\
\hline JPN & 54.8 & 32.2 & 12.4 & 0.0 & 0.5 & 11 & 23 & 12 & 0 & 1 \\
\hline KOR & 68.3 & 24.1 & 7.6 & 0.0 & 0.0 & 7 & 7 & 3 & 0 & 0 \\
\hline LTU & 0.0 & 54.8 & 21.0 & 5.2 & 19.1 & 0 & 3 & 2 & 1 & 4 \\
\hline LUX & 0.0 & 100.0 & 0.0 & 0.0 & 0.0 & 0 & 1 & 0 & 0 & 0 \\
\hline LVA & 0.0 & 50.6 & 27.0 & 12.1 & 10.3 & 0 & 2 & 2 & 1 & 1 \\
\hline MEX & 34.1 & 35.9 & 9.1 & 0.0 & 20.9 & 14 & 64 & 22 & 0 & 109 \\
\hline NLD & 25.7 & 63.8 & 10.6 & 0.0 & 0.0 & 8 & 23 & 9 & 0 & 0 \\
\hline NOR & 0.0 & 51.8 & 0.0 & 3.2 & 45.0 & 0 & 6 & 0 & 1 & 12 \\
\hline POL & 16.1 & 35.1 & 28.7 & 7.0 & 13.0 & 8 & 24 & 20 & 7 & 13 \\
\hline PRT & 26.3 & 29.8 & 21.2 & 0.0 & 22.7 & 1 & 5 & 6 & 0 & 13 \\
\hline SVK & 0.0 & 11.2 & 88.8 & 0.0 & 0.0 & 0 & 1 & 7 & 0 & 0 \\
\hline SVN & 0.0 & 40.6 & 15.2 & 0.0 & 44.2 & 0 & 2 & 2 & 0 & 8 \\
\hline SWE & 22.2 & 46.4 & 6.4 & 0.0 & 24.9 & 1 & 7 & 2 & 0 & 11 \\
\hline USA & 59.2 & 27.2 & 6.7 & 0.0 & 6.9 & 31 & 69 & 23 & 0 & 56 \\
\hline OECD & 42.0 & 33.9 & 13.0 & 0.8 & 10.3 & 276 & 715 & 362 & 38 & 759 \\
\hline
\end{tabular}


Table B.2. 100 thousand inhabitants (metro threshold) with 60 minute drive

\begin{tabular}{|c|c|c|c|c|c|c|c|c|c|c|}
\hline \multirow{3}{*}{ Country } & \multicolumn{5}{|c|}{ Population Living in TL3 Regions } & \multicolumn{5}{|c|}{ Number of TL3 Regions } \\
\hline & \multicolumn{2}{|c|}{ MR } & \multicolumn{3}{|c|}{ NMR } & \multicolumn{2}{|c|}{ MR } & \multicolumn{3}{|c|}{ NMR } \\
\hline & MR-L $(\%)$ & MR-M (\%) & NM-M (\%) & NM-S (\%) & NM-R (\%) & MR-L & MR-M & NM-M & NM-S & $\mathrm{NM}-\mathrm{R}$ \\
\hline AUS & 56.8 & 20.8 & 1.1 & 0.0 & 21.3 & 4 & 14 & 1 & 0 & 31 \\
\hline AUT & 31.3 & 24.4 & 32.2 & 0.0 & 12.1 & 5 & 6 & 15 & 0 & 9 \\
\hline BEL & 22.4 & 40.5 & 35.7 & 1.0 & 0.4 & 4 & 13 & 24 & 2 & 1 \\
\hline CAN & 43.4 & 28.6 & 3.9 & 0.0 & 24.1 & 28 & 41 & 24 & 0 & 200 \\
\hline CHE & 0.0 & 43.8 & 49.6 & 0.0 & 6.5 & 0 & 7 & 16 & 0 & 3 \\
\hline $\mathrm{CHL}$ & 40.5 & 48.5 & 3.3 & 0.0 & 7.7 & 5 & 23 & 3 & 0 & 23 \\
\hline CZE & 24.6 & 28.1 & 44.5 & 2.8 & 0.0 & 2 & 3 & 8 & 1 & 0 \\
\hline DEU & 30.7 & 42.8 & 22.8 & 0.3 & 3.4 & 62 & 177 & 129 & 3 & 31 \\
\hline DNK & 35.4 & 33.4 & 30.4 & 0.0 & 0.7 & 4 & 3 & 3 & 0 & 1 \\
\hline ESP & 35.1 & 37.4 & 24.9 & 1.2 & 1.5 & 4 & 23 & 20 & 3 & 9 \\
\hline EST & 0.0 & 42.6 & 24.9 & 11.5 & 21.1 & 0 & 1 & 1 & 1 & 2 \\
\hline FIN & 0.0 & 67.0 & 3.3 & 0.0 & 29.7 & 0 & 7 & 1 & 0 & 11 \\
\hline FRA & 25.8 & 48.4 & 16.8 & 0.0 & 9.0 & 10 & 44 & 24 & 0 & 23 \\
\hline GBR & 36.5 & 38.8 & 19.0 & 0.0 & 5.7 & 51 & 63 & 39 & 0 & 20 \\
\hline GRC & 38.2 & 21.8 & 1.5 & 10.1 & 28.5 & 6 & 7 & 1 & 7 & 31 \\
\hline HUN & 30.2 & 31.3 & 23.8 & 12.6 & 2.1 & 2 & 8 & 5 & 4 & 1 \\
\hline IRL & 39.4 & 14.2 & 17.7 & 10.8 & 17.8 & 2 & 1 & 2 & 1 & 2 \\
\hline ISL & 0.0 & 86.4 & 0.0 & 0.0 & 13.6 & 0 & 4 & 0 & 0 & 4 \\
\hline ITA & 22.5 & 31.7 & 39.8 & 1.8 & 4.1 & 6 & 33 & 53 & 4 & 14 \\
\hline JPN & 54.8 & 32.2 & 12.4 & 0.0 & 0.5 & 11 & 23 & 12 & 0 & 1 \\
\hline KOR & 68.3 & 24.1 & 7.6 & 0.0 & 0.0 & 7 & 7 & 3 & 0 & 0 \\
\hline LTU & 0.0 & 54.8 & 21.0 & 5.2 & 19.1 & 0 & 3 & 2 & 1 & 4 \\
\hline LUX & 0.0 & 100.0 & 0.0 & 0.0 & 0.0 & 0 & 1 & 0 & 0 & 0 \\
\hline LVA & 0.0 & 50.6 & 27.0 & 12.1 & 10.3 & 0 & 2 & 2 & 1 & 1 \\
\hline MEX & 34.1 & 35.9 & 11.1 & 0.0 & 19.0 & 14 & 64 & 33 & 0 & 98 \\
\hline NLD & 25.7 & 63.8 & 10.6 & 0.0 & 0.0 & 8 & 23 & 9 & 0 & 0 \\
\hline NOR & 0.0 & 51.8 & 10.9 & 3.2 & 34.1 & 0 & 6 & 2 & 1 & 10 \\
\hline POL & 16.1 & 35.1 & 36.0 & 3.6 & 9.2 & 8 & 24 & 27 & 4 & 9 \\
\hline PRT & 26.3 & 29.8 & 27.5 & 0.0 & 16.4 & 1 & 5 & 8 & 0 & 11 \\
\hline SVK & 0.0 & 11.2 & 88.8 & 0.0 & 0.0 & 0 & 1 & 7 & 0 & 0 \\
\hline SVN & 0.0 & 40.6 & 52.0 & 0.0 & 7.3 & 0 & 2 & 8 & 0 & 2 \\
\hline SWE & 22.2 & 46.4 & 9.6 & 0.0 & 21.7 & 1 & 7 & 3 & 0 & 10 \\
\hline USA & 59.2 & 27.2 & 6.7 & 0.0 & 6.9 & 31 & 69 & 23 & 0 & 56 \\
\hline OECD & 42.0 & 33.9 & 15.5 & 0.6 & 8.0 & 276 & 715 & 508 & 33 & 618 \\
\hline
\end{tabular}


Table B.3. 250 thousand inhabitants (metro threshold) with 45 minute drive

\begin{tabular}{|c|c|c|c|c|c|c|c|c|c|c|}
\hline \multirow{3}{*}{ Country } & \multicolumn{5}{|c|}{ Population Living in TL3 Regions } & \multicolumn{5}{|c|}{ Number of TL3 Regions } \\
\hline & \multicolumn{2}{|c|}{ MR } & \multicolumn{3}{|c|}{ NMR } & \multicolumn{2}{|c|}{ MR } & \multicolumn{3}{|c|}{ NMR } \\
\hline & MR-L (\%) & MR-M (\%) & NM-M (\%) & NM-S (\%) & NM-R $(\%)$ & MR-L & MR-M & NM-M & NM-S & NM-R \\
\hline AUS & 56.8 & 13.8 & 1.1 & 7.0 & 21.3 & 4 & 6 & 1 & 8 & 31 \\
\hline AUT & 31.3 & 23.5 & 5.1 & 5.5 & 34.7 & 5 & 6 & 2 & 3 & 19 \\
\hline BEL & 22.4 & 23.8 & 47.6 & 4.2 & 1.9 & 4 & 6 & 25 & 5 & 4 \\
\hline CAN & 43.4 & 22.5 & 1.9 & 5.6 & 26.6 & 28 & 31 & 7 & 13 & 214 \\
\hline $\mathrm{CHE}$ & 0.0 & 50.3 & 14.9 & 23.1 & 11.8 & 0 & 6 & 3 & 10 & 7 \\
\hline $\mathrm{CHL}$ & 40.5 & 29.8 & 0.0 & 21.3 & 8.3 & 5 & 9 & 0 & 16 & 24 \\
\hline CZE & 24.6 & 32.3 & 0.0 & 43.1 & 0.0 & 2 & 4 & 0 & 8 & 0 \\
\hline DEU & 30.7 & 37.0 & 13.8 & 7.9 & 10.6 & 62 & 145 & 75 & 44 & 76 \\
\hline DNK & 35.4 & 33.4 & 0.0 & 0.0 & 31.2 & 4 & 3 & 0 & 0 & 4 \\
\hline ESP & 35.1 & 33.8 & 6.3 & 22.5 & 2.4 & 4 & 16 & 4 & 24 & 11 \\
\hline EST & 0.0 & 42.6 & 0.0 & 36.3 & 21.1 & 0 & 1 & 0 & 2 & 2 \\
\hline FIN & 0.0 & 46.1 & 0.0 & 20.9 & 33.0 & 0 & 3 & 0 & 4 & 12 \\
\hline FRA & 25.8 & 40.2 & 5.3 & 13.7 & 15.0 & 10 & 31 & 5 & 21 & 34 \\
\hline GBR & 35.4 & 32.5 & 16.3 & 5.7 & 10.1 & 50 & 52 & 31 & 9 & 31 \\
\hline GRC & 39.6 & 9.6 & 0.0 & 21.4 & 29.4 & 7 & 1 & 0 & 12 & 32 \\
\hline HUN & 30.2 & 20.3 & 0.0 & 45.1 & 4.4 & 2 & 4 & 0 & 12 & 2 \\
\hline IRL & 39.4 & 14.2 & 0.0 & 28.6 & 17.8 & 2 & 1 & 0 & 3 & 2 \\
\hline ISL & 0.0 & 0.0 & 0.0 & 86.4 & 13.6 & 0 & 0 & 0 & 4 & 4 \\
\hline ITA & 22.5 & 24.1 & 11.8 & 32.4 & 9.2 & 6 & 17 & 12 & 50 & 25 \\
\hline JPN & 54.8 & 29.6 & 14.6 & 0.4 & 0.5 & 11 & 21 & 13 & 1 & 1 \\
\hline KOR & 68.3 & 21.2 & 7.4 & 3.1 & 0.0 & 7 & 6 & 3 & 1 & 0 \\
\hline LTU & 0.0 & 46.5 & 0.0 & 34.5 & 19.1 & 0 & 2 & 0 & 4 & 4 \\
\hline LUX & 0.0 & 100.0 & 0.0 & 0.0 & 0.0 & 0 & 1 & 0 & 0 & 0 \\
\hline LVA & 0.0 & 31.0 & 0.0 & 58.7 & 10.3 & 0 & 1 & 0 & 4 & 1 \\
\hline MEX & 34.1 & 30.8 & 7.9 & 6.2 & 21.0 & 14 & 49 & 17 & 19 & 110 \\
\hline NLD & 21.7 & 31.7 & 23.4 & 22.6 & 0.6 & 6 & 8 & 14 & 11 & 1 \\
\hline NOR & 0.0 & 42.4 & 5.9 & 6.6 & 45.0 & 0 & 4 & 1 & 2 & 12 \\
\hline POL & 16.1 & 33.6 & 4.6 & 31.6 & 14.1 & 8 & 21 & 3 & 26 & 14 \\
\hline PRT & 26.3 & 21.1 & 14.5 & 15.4 & 22.7 & 1 & 2 & 4 & 5 & 13 \\
\hline SVK & 0.0 & 25.8 & 0.0 & 74.2 & 0.0 & 0 & 2 & 0 & 6 & 0 \\
\hline SVN & 0.0 & 40.6 & 9.8 & 5.4 & 44.2 & 0 & 2 & 1 & 1 & 8 \\
\hline SWE & 22.2 & 33.5 & 2.9 & 16.5 & 24.9 & 1 & 3 & 1 & 5 & 11 \\
\hline USA & 59.2 & 25.0 & 6.6 & 2.4 & 6.9 & 31 & 59 & 18 & 15 & 56 \\
\hline OECD & 41.9 & 28.9 & 8.9 & 9.9 & 10.4 & 274 & 523 & 240 & 348 & 765 \\
\hline
\end{tabular}


Table B.4. 500 thousand inhabitants (metro threshold) with 45 minute drive

\begin{tabular}{|c|c|c|c|c|c|c|c|c|c|c|}
\hline \multirow{3}{*}{ Country } & \multicolumn{5}{|c|}{ Population Living in TL3 Regions } & \multicolumn{5}{|c|}{ Number of TL3 Regions } \\
\hline & \multicolumn{2}{|c|}{ MR } & \multicolumn{3}{|c|}{ NMR } & \multicolumn{2}{|c|}{ MR } & \multicolumn{3}{|c|}{ NMR } \\
\hline & MR-L (\%) & MR-M (\%) & NM-M (\%) & NM-S (\%) & NM-R (\%) & MR-L & MR-M & NM-M & NM-S & NM-R \\
\hline AUS & 56.8 & 8.1 & 0.0 & 13.8 & 21.3 & 4 & 2 & 0 & 13 & 31 \\
\hline AUT & 31.3 & 9.0 & 1.8 & 23.2 & 34.7 & 5 & 2 & 1 & 8 & 19 \\
\hline BEL & 22.4 & 24.8 & 47.1 & 3.8 & 1.9 & 4 & 7 & 24 & 5 & 4 \\
\hline CAN & 43.4 & 17.7 & 2.8 & 9.5 & 26.6 & 28 & 22 & 7 & 22 & 214 \\
\hline CHE & 0.0 & 29.6 & 11.4 & 49.3 & 9.7 & 0 & 4 & 2 & 14 & 6 \\
\hline $\mathrm{CHL}$ & 40.5 & 11.6 & 0.0 & 39.6 & 8.3 & 5 & 3 & 0 & 22 & 24 \\
\hline CZE & 24.6 & 22.7 & 0.0 & 52.7 & 0.0 & 2 & 2 & 0 & 10 & 0 \\
\hline DEU & 30.7 & 20.3 & 10.4 & 27.8 & 10.7 & 62 & 73 & 50 & 140 & 77 \\
\hline DNK & 35.4 & 0.0 & 0.0 & 33.4 & 31.2 & 4 & 0 & 0 & 3 & 4 \\
\hline ESP & 35.1 & 17.5 & 3.1 & 41.9 & 2.4 & 4 & 8 & 1 & 35 & 11 \\
\hline EST & 0.0 & 42.6 & 0.0 & 36.3 & 21.1 & 0 & 1 & 0 & 2 & 2 \\
\hline FIN & 0.0 & 28.4 & 0.0 & 38.6 & 33.0 & 0 & 1 & 0 & 6 & 12 \\
\hline FRA & 25.8 & 22.4 & 3.2 & 34.1 & 14.5 & 10 & 12 & 3 & 43 & 33 \\
\hline GBR & 36.5 & 23.2 & 10.6 & 18.9 & 10.8 & 51 & 37 & 19 & 34 & 32 \\
\hline GRC & 38.2 & 9.6 & 1.5 & 21.4 & 29.4 & 6 & 1 & 1 & 12 & 32 \\
\hline HUN & 30.2 & 0.0 & 0.0 & 65.4 & 4.4 & 2 & 0 & 0 & 16 & 2 \\
\hline IRL & 39.4 & 0.0 & 0.0 & 42.8 & 17.8 & 2 & 0 & 0 & 4 & 2 \\
\hline ISL & 0.0 & 0.0 & 0.0 & 86.4 & 13.6 & 0 & 0 & 0 & 4 & 4 \\
\hline ITA & 22.5 & 15.2 & 6.7 & 46.4 & 9.2 & 6 & 9 & 7 & 63 & 25 \\
\hline JPN & 54.8 & 19.9 & 16.4 & 7.7 & 1.2 & 11 & 16 & 9 & 9 & 2 \\
\hline KOR & 68.3 & 11.3 & 13.4 & 7.0 & 0.0 & 7 & 3 & 4 & 3 & 0 \\
\hline LTU & 0.0 & 26.5 & 0.0 & 54.4 & 19.1 & 0 & 1 & 0 & 5 & 4 \\
\hline LUX & 0.0 & 100.0 & 0.0 & 0.0 & 0.0 & 0 & 1 & 0 & 0 & 0 \\
\hline LVA & 0.0 & 50.6 & 0.0 & 39.1 & 10.3 & 0 & 2 & 0 & 3 & 1 \\
\hline MEX & 34.1 & 22.1 & 6.1 & 16.6 & 21.1 & 14 & 30 & 11 & 43 & 111 \\
\hline NLD & 25.7 & 20.7 & 33.5 & 19.5 & 0.6 & 8 & 6 & 16 & 9 & 1 \\
\hline NOR & 0.0 & 23.9 & 0.0 & 31.0 & 45.0 & 0 & 2 & 0 & 5 & 12 \\
\hline POL & 16.1 & 20.1 & 3.1 & 45.0 & 15.6 & 8 & 12 & 2 & 35 & 15 \\
\hline PRT & 26.3 & 16.7 & 12.5 & 21.8 & 22.7 & 1 & 1 & 3 & 7 & 13 \\
\hline SVK & 0.0 & 11.2 & 0.0 & 88.8 & 0.0 & 0 & 1 & 0 & 7 & 0 \\
\hline SVN & 0.0 & 25.0 & 9.8 & 21.1 & 44.2 & 0 & 1 & 1 & 2 & 8 \\
\hline SWE & 22.2 & 29.9 & 2.9 & 20.0 & 24.9 & 1 & 2 & 1 & 6 & 11 \\
\hline USA & 59.2 & 19.0 & 5.1 & 9.8 & 6.9 & 31 & 36 & 8 & 48 & 56 \\
\hline OECD & 42.0 & 19.0 & 7.6 & 20.8 & 10.6 & 276 & 298 & 170 & 638 & 768 \\
\hline
\end{tabular}


Table B.5. Half million inhabitants (metro threshold) with 60 minute drive

\begin{tabular}{|c|c|c|c|c|c|c|c|c|c|c|}
\hline \multirow{3}{*}{ Country } & \multicolumn{5}{|c|}{ Population Living in TL3 Regions } & \multicolumn{5}{|c|}{ Number of TL3 Regions } \\
\hline & \multicolumn{2}{|c|}{ MR } & \multicolumn{3}{|c|}{ NMR } & \multicolumn{2}{|c|}{ MR } & \multicolumn{3}{|c|}{ NMR } \\
\hline & MR-L (\%) & MR-M (\%) & NM-M (\%) & NM-S (\%) & NM-R (\%) & MR-L & MR-M & NM-M & NM-S & NM-R \\
\hline AUS & 56.8 & 8.1 & 0.0 & 13.8 & 21.3 & 4 & 2 & 0 & 13 & 31 \\
\hline AUT & 31.3 & 9.0 & 10.4 & 37.2 & 12.1 & 5 & 2 & 4 & 15 & 9 \\
\hline BEL & 22.4 & 24.8 & 49.9 & 2.5 & 0.4 & 4 & 7 & 27 & 5 & 1 \\
\hline CAN & 43.4 & 17.7 & 5.9 & 9.0 & 24.1 & 28 & 22 & 14 & 29 & 200 \\
\hline $\mathrm{CHE}$ & 0.0 & 29.6 & 27.7 & 36.1 & 6.5 & 0 & 4 & 7 & 12 & 3 \\
\hline $\mathrm{CHL}$ & 40.5 & 11.6 & 0.9 & 40.2 & 6.8 & 5 & 3 & 1 & 23 & 22 \\
\hline CZE & 24.6 & 22.7 & 0.0 & 52.7 & 0.0 & 2 & 2 & 0 & 10 & 0 \\
\hline DEU & 30.7 & 20.3 & 22.2 & 22.9 & 3.9 & 62 & 73 & 110 & 124 & 33 \\
\hline DNK & 35.4 & 0.0 & 0.0 & 53.5 & 11.0 & 4 & 0 & 0 & 5 & 2 \\
\hline ESP & 35.1 & 17.5 & 9.8 & 35.6 & 2.0 & 4 & 8 & 5 & 32 & 10 \\
\hline EST & 0.0 & 42.6 & 0.0 & 36.3 & 21.1 & 0 & 1 & 0 & 2 & 2 \\
\hline FIN & 0.0 & 28.4 & 0.0 & 38.6 & 33.0 & 0 & 1 & 0 & 6 & 12 \\
\hline FRA & 25.8 & 22.4 & 6.8 & 34.3 & 10.8 & 10 & 12 & 6 & 47 & 26 \\
\hline GBR & 36.5 & 23.2 & 20.0 & 14.6 & 5.7 & 51 & 37 & 38 & 27 & 20 \\
\hline GRC & 38.2 & 9.6 & 1.5 & 22.4 & 28.5 & 6 & 1 & 1 & 13 & 31 \\
\hline HUN & 30.2 & 0.0 & 4.2 & 63.5 & 2.1 & 2 & 0 & 1 & 16 & 1 \\
\hline IRL & 39.4 & 0.0 & 0.0 & 42.8 & 17.8 & 2 & 0 & 0 & 4 & 2 \\
\hline ISL & 0.0 & 0.0 & 0.0 & 86.4 & 13.6 & 0 & 0 & 0 & 4 & 4 \\
\hline ITA & 22.5 & 15.2 & 22.2 & 35.0 & 5.1 & 6 & 9 & 24 & 56 & 15 \\
\hline JPN & 54.8 & 19.9 & 17.0 & 7.7 & 0.5 & 11 & 16 & 10 & 9 & 1 \\
\hline KOR & 68.3 & 11.3 & 13.4 & 7.0 & 0.0 & 7 & 3 & 4 & 3 & 0 \\
\hline LTU & 0.0 & 26.5 & 0.0 & 59.8 & 13.7 & 0 & 1 & 0 & 6 & 3 \\
\hline LUX & 0.0 & 100.0 & 0.0 & 0.0 & 0.0 & 0 & 1 & 0 & 0 & 0 \\
\hline LVA & 0.0 & 50.6 & 0.0 & 39.1 & 10.3 & 0 & 2 & 0 & 3 & 1 \\
\hline MEX & 34.1 & 22.1 & 8.2 & 16.4 & 19.3 & 14 & 30 & 18 & 46 & 101 \\
\hline NLD & 25.7 & 20.7 & 43.9 & 9.7 & 0.0 & 8 & 6 & 21 & 5 & 0 \\
\hline NOR & 0.0 & 23.9 & 10.9 & 31.0 & 34.1 & 0 & 2 & 2 & 5 & 10 \\
\hline POL & 16.1 & 20.1 & 8.1 & 46.3 & 9.3 & 8 & 12 & 6 & 37 & 9 \\
\hline PRT & 26.3 & 16.7 & 21.9 & 19.8 & 15.3 & 1 & 1 & 6 & 7 & 10 \\
\hline SVK & 0.0 & 11.2 & 10.3 & 78.5 & 0.0 & 0 & 1 & 1 & 6 & 0 \\
\hline SVN & 0.0 & 25.0 & 34.5 & 33.1 & 7.3 & 0 & 1 & 5 & 4 & 2 \\
\hline SWE & 22.2 & 29.9 & 6.5 & 16.5 & 24.9 & 1 & 2 & 2 & 5 & 11 \\
\hline USA & 59.2 & 19.0 & 5.2 & 9.7 & 6.9 & 31 & 36 & 9 & 47 & 56 \\
\hline OECD & 42.0 & 19.0 & 11.5 & 19.3 & 8.3 & 276 & 298 & 322 & 626 & 628 \\
\hline
\end{tabular}

